\title{
Aplikasi Monitoring Pelayanan Masyarakat Desa Sumberanyar Kecamatan Paiton Berbasis Web
}

\author{
Ruly Amalia*1, Anis Yusrotun N. ${ }^{2}$, Wali Ja'far Shudiq ${ }^{3}$ \\ ${ }^{1,2,3}$ Program Studi Teknik Informatika, Fakultas Teknik, Universitas Nurul \\ Jadid Karanganyar Paiton Probolinggo \\ e-mail: *11amaliaruly6555@gmail.com, ${ }^{2}$ ayusrotun@gmail.com, ${ }^{3}$ wali.jafar@unuja.ac.id
}

\begin{abstract}
Abstrak
Pelayanan masyarakat merupakan suatu tugas yang harus dilaksanakan oleh pemerintah. Akan tetapi pelayanan masyarakat yang ada di desa sumberanyar khususnya dalam menanggapi sebuah aspirasi dan pengaduan seperti pengaduan tentang bantuan sosial, infrastruktur dan pengaduan yang lainnya masih dilakukan secara manual dan belum terpublikasi secara baik, salah satu faktornya adalah waktu. Jarak alamat rumah dengan kantor desa menjadi faktor penghalang mereka serta luasnya daerah sumberanyar menjadi kendala dan masyarakat harus menunggu waktu yng lama pengaduan mereka di proses. Dari penjelasan tersbut maka perlu suatu aplikasi yang bisa memudahkan masyarakat dalam melakukan pelayanan aspirasi, aplikasi monitoring pelayanan masyarakat desa sumberanyar kecamatan paiton berbasis web adalah solusi untuk mengatasi permasalahan yang telah diuraikan. Aplikasi ini dibangun dengan menggunakan model SLDC (Software Development Life Cycle). Dari hasil penelitian ini disimpulkan bahwa aplikasi tersebut sangat layak untuk digunakan oleh aparatur desa dalam memonitoring pelayanan masyyarakat serta semua fitur pada aplikasi bias digunakan dengan baik
\end{abstract}

Kata kunci: Pelayanan, Waterfall, aspirasi.

\begin{abstract}
Community service is a task that must be carried out by the government. However, community services in Sumberanyar Village, especially in responding to aspirations and complaints such as complaints about social assistance, infrastructure and other complaints are still done manually and have not been published properly, one of the factors is time. The distance from their home address to the village office is a barrier factor for them and the size of the source area is an obstacle and the community has to wait a long time for their complaints to be processed. Therefore, it is necessary to have an application that can facilitate the community in carrying out aspiration services, the web-based application for monitoring community services in Sumberanyar Village, Paiton District, is a solution to overcome the problems that have been described. This application is built using the SLDC (Software Development Life Cycle) model. From the results of this study it was concluded that the application is very feasible to be used by village officials in monitoring community services and all features in the application can be used properly.
\end{abstract}

Keyword: Service, Waterfall, aspirations

\section{PENDAHULUAN}

Dengan melihat teknologi yang semakin brkembang saat ini terus meningkat pada masyarakat desa sumberanyar kecamatan paiton. Agar pengabdian kepada masyarakat desa dapat terlaksana dengan baik, maka organisasi setingkat desa dapat berpartisipasi langsung dalam memberikan pelayanan kepada warga sesuai dengan tugas dan fungsinya masing- 
masing, sehingga masyarakat merasa puas dengan pelayanan yang diberikan oleh desa. Peralatan dan layanan diharapkan dapat beroperasi dengan cara terbaik. [1].

Desa Sumberanyar merupakan desa yang terletak di kecamatan Paiton - Probolinggo, bernagai macam kegiatan pemerintahan yang dilakukan di desa sumberanyar salah satunya adalah pelaksanaan administrasi kependudukan serta pelayanan masyarakat desa [2]. Pada penelitian pertama yang dilakukan oleh sindy salma dalam jurnalnya yang berjudul "Sistem Informasi Monitoring Pelayanan Di Badan Pertanahan Nasional Kota Cimahi" penulis menjelaskan bahwa prroses pelayanannya yang masih kesulitan dalam melayani masyarakat untuk memberikan informasi mengenai pelayanan yang diberikan oleh kantor BPN yaitu keinginan masyarakat yang inigin mengetahui proses permohonan pengerjaannya. Dengan menggunakan metode waterfall dan hasil, yang didapat adalah upaya untuk meningkatkan sistem informasi yang dapat mempermudah pihak kepala kantor dan kepala bidang tata usaha agar dapat melakukan permintaan pelayanannya kepada masyarakat [3]. Pada penelitian kedua yang dilakukan oleh ika istiningsih dalam jurnalnya yang berjudul "Sistem Informasi Monitoring Pelayanan Di Kantor Kecamatan Bulu" penulis menjelaskan bahwa masyarakat masih harus datang ke kantor mengantri lama dan menunggu tanpa ada kepastian yang jelas. Pada bagian pelayananannya dalam proses pencarian data salah satunya permohonanan pelayanan dan pengurusan kartu penduduk masih kesulitan mengurus dokumen. Dengan menggunakan metode Unified Modelling Language (UML) dan menggunakan analisa PIECES. hasil dari penelitian ini adalah membuat aplikasi yang memudahkan masyarakat memantau sistem pelayanan [4]. Pada penelitian ketiga dilakukan oleh okta lesva dalam jurnalnya yang berjudul "Sistem Monitoring Kesehatan Masyarakat Berbasis Web" petugas puskemas pajar bulan harus memberikan edukasi dan informasi yang akurat mengenai informasi kesehatan dan data pasien. Metodde penelitian ini mengunakan web engineering customer communication, planning, modelling construction. Hasil dari penelitian ini adalah membuat sistem monitoring yang dapat mempermudah masyarakat melakukan pendaftaran secara online dimana saja [5].

Perangkat desa merupakan aparatur pelayanan publik yang mengemban kewajiban dan tanggung jawab melayani masyarakat, oleh karena itu panitia desa dituntut untuk bertanggung jawab, cakap, dan terampil, serta memiliki empati yang tinggi dalam menjalankan tugasnya melayani masyarakat [6]. Desa Sumberanyar telah menerapkan sistem informasi pemantauan desa, namun belum sesuai dengan berbagai kebutuhan masyarakat. Sistem ini memiliki banyak kelebihan, di antaranya dapat meminimalkan risiko kesalahan penulisan identitas dengan lebih akurat. Namun kelemahan dari sistem tersebut adalah tidak dapat memberikan pelayanan kepada warga selama 24 jam sehari. Hal ini karena untuk masuk ke sistem, masyarakat harus langsung ke kantor desa, dan waktu kerja organisasi tingkat desa hanya 5 hari, dan ada batasan. Terdapat beberapa kendala sistem yang perlu diselesaikan yaitu, ketidakmampuan menangani imbauan masyarakat sebagian besar masyarakat Desa Sumberanyar secara manual, dan tampilan laporan pengaduan yang sudah diproses. [7].

Dari penjelasan di atas, maka dengan adanya sistem yang dapat mempermudah aparatur desa sumberanyar dalam melakukan pelayanan serta mempermudah dalam menanggapi aspirasi pelayanan masyarakat desa. Dengan adanya sistem monitoring masyarakat secara komputerisasi dimana dalam pengaduan tersebut akan ada sebuah pengajuan dari masyarakat desa kemudian akan di monitoring oleh aparatur desa. Selain itu dengan adanya sebuah apikasi ini semua informasi akan berjalan dengan akurat dan mempermudah sistematis data yang secara terstruktur serta baik. Diharapkan dengan melakukan penelitian ini dapat di ambil manfaat seperti memudahkan masyarakat desa sumberanyar dalam menyampaikan aspirasi pengaduan terutama tentang bantuan sosial, infrastruktur dan lainnya.

Amalia, et., al [Aplikasi Monitoring Pelayanan Masyarakat Desa Sumberanyar Kecamatan Paiton Berbasis Web] 


\section{.2. METODE PENELITIAN}

Peneliti menggunakan Metode kualitatif dan model SLDC waterfall, dengan tujuannya adalah untuk mengumpulkan data mengenai pelayanan masyarakat di Desa Sumberanyar Kecamatan Paiton. Metode penelitian kualitatif adalah penelitian yang dimana alat utamanya adalah peneliti, dipadukan menggunakan teknologi pengumpulan data [8].

Model Waterfall adalah model pengembangan software yang berkelanjutan di mana setia tahapannya dilihat sebagai aliran dari atas ke bawah terus menerus (seperti air terjun) mulai dari tahapan analisis, desain, coding, dan pengujian. Dalam pengembangannya, metode waterfall memiliki beberapa proses yang urut seperti air terjun dimana prosesnya dimulai dari kebutuhan analisa (requirements analysis), desain sistem (system design), pengkodean dan pengujian, implementasi program, dan pemeliharaan [9].

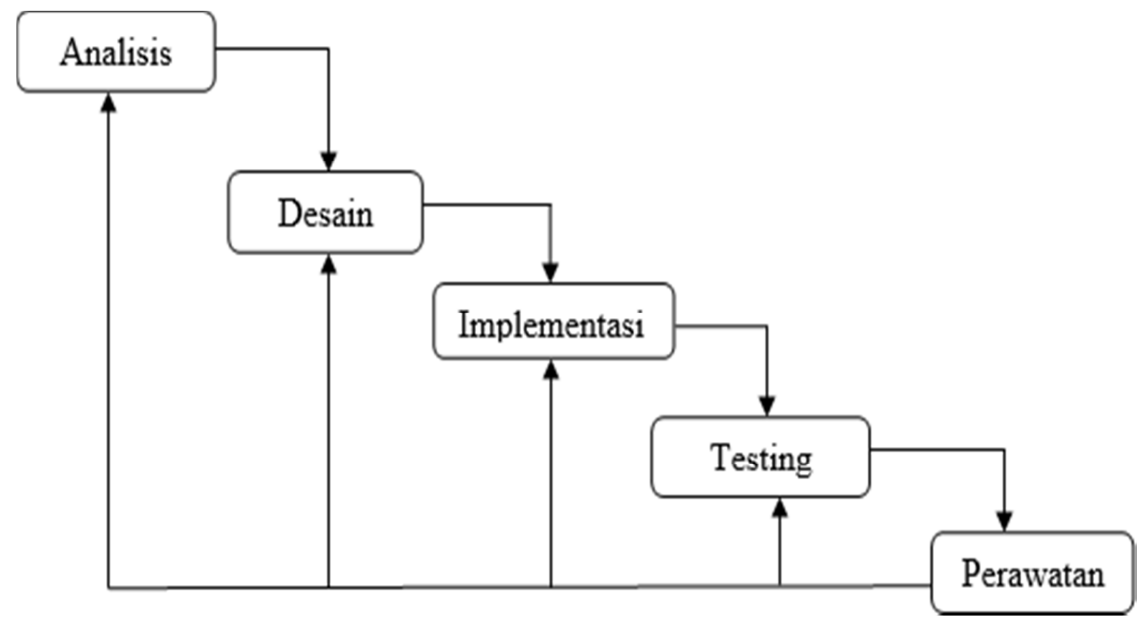

Gambar 1. Model Waterfall [9]

\subsection{Analisis}

Rekayasa Kebutuhan merupakan batasan sistem yang akan beroperasi dan dikembangkan dari proses membentuk layanan yang dibutuhkan masyarakat dari suatu sistem. Dalam proses analisis ini dilakukan dengan cara survei ke lapangan atau observasi dan tanya jawab atau wawancara.

a. Obervasi

Observasi dilakukan untuk mengetahui dan mengidentifikasi kondisi pelayanan di kantor Desa Sumberanyar Kecamatan Paiton.

b. Wawancara

Wawancara dilaksanakan secara langsung dengan bapak Moh. Toha, S.Pd.I,Mm selaku kepala desa Sumberanyar Kecamatan Paiton. Wawancara dilakukan untuk mendapatkan data lebih lanjut tentang alur sistem pengaduan masyarakat yang sedang berjalan di kantor desa Sumberanyar

\subsection{Desain}

Berdasarkan kebutuhan fungsional dan non fungsional yang telah peneliti peroleh pada tahap sebelumnya, maka perancangan sistem akan dikembangkan pada tahap ini. Untuk itu diperlukan kerja keras untuk merancang sistem komputerisasi yang akan mampu memaksimalkan aplikasi yang dijalankan agar mendapatkan hasil yang sesuai harapan. Ada beberapa hal dalam desain sistem yaitu System Flowcharts. 


\subsection{Implementasi}

Setelah tahap desain dari aplikasi berhasil dibuat, proses selanjutnya adalah mengimplementasikan desain yang telah dibuat menjadi kode program. Dalam penelitian ini di implementasikan pada website dan menggunakan PHP sebagai bahasa pemrograman serta menggunakan framework Codeigniter. Sedangkan MYSQL digunakan sebagai basis data

\subsection{Testing atau Pengujian}

Tahapan selanjutnya adalah melakukan testing. Pengujian Aplikasi Monitoring Pelayanan Masyarakat Desa Sumberanyar Kecamatan Paiton Berbasis Web. Hal ini dilakukan untuk mengetahui bagaimana penerapan desain sistem ini apakah sudah sesuai atau tidak. Pengujian yang akan dilakukan salah satunya dengan pengujian internal (black box testing) dan pengujian eksternal (user).

\subsection{Perawatan (Maintenance)}

Setelah dikatakan layak untuk digunakan dan sistem telah melewati tahapan pengujian maka tahapan selanjutnya adalah melakukan maintenance. Melakukan melakukan instalasi sistem informasi pengaduan masyarakat desa sumberanyar kecamatan paiton berbasis android sebagai langkah pertama dalam melakukan maintenance. Dalam penelitian ini, sistem informasi pengaduan yang telah diciptakan akan di upload dan dipasang pada server yang telah disediakan oleh desa sumberanyar [10].

\section{HASIL DAN PEMBAHASAN}

Peneliti melakukan Obervasi, Wawancara dan Studi Pustaka guna untuk mengumpulkan data. Hasil dari pengumpulan data yang peneliti lakukan dijelaskan sebagai berikut :

\subsection{Analisis}

a. Observasi

Observasi dilakukan dengan mengamati proses pengaduan mengenai pelayanan masyarakat tentang aspirasi pelayanan yang dilakukan saat ini oleh Kantor Desa Sumberanyar Kecamatan Paiton. Hasil laporan dari observasi masyarakat Desa Sumberanyar mengenai aspirasi tentang pelayanan pengaduan yang ada di desa sumberanyar masih dilakukan dengan datang ke kantor kemudian menemui kepala desa dan aparatur desa demi mengajukan pengaduan apa saja yang ingin di adukan. Sehingga para warga desa sumberanyar masih kesulitan dengan adanya sistem yang saat ini dilakukan.

b. Wawancara

Salah satu Teknik dalam tahapan pengumpulan data dengan cara peneliti bertanya secara langsung kepada pihak yang bersangkutan disebut wawancara. Pada metode ini dilakukan wawancara langsung dengan Bapak Moh.Toha,S.Pd.I,MM dan wawancara langsung dengan para warga atau masyarakat desa sumberanyar kecamatan paiton, sehingga diperoleh data pelengkap dan pendukung data hasil observasi. Dari wawancara yang dilakukan dapat disimpulkan bahwa Sistem pengaduan yanng dilakukan saat ini masih menggunakan sistem manual dan juga mengenai laporan yang disampaikan oleh setiap aparatur harus mengumpulkan warganya terlebih dahulu agar semua mengetahui tentang aspirasi apa saja yang masyarakat keluhkan. Dengan hasil laporan mengenai aspirasi tentang pelayanan masyarakat yang disampaikan dengan menggunakan surat.

\footnotetext{
Amalia, et., al [Aplikasi Monitoring Pelayanan Masyarakat Desa Sumberanyar Kecamatan Paiton Berbasis Web]
} 


\subsection{Desain}

Setelah melakukan tahapan analisis sistem maka langkah selanjutnya yang akan dilakukan yaitu dalam penelitian ini dengan cara pembuatan Flowchart. Dimana peneliti membuat bagan alur sistem lama dan bagan alur sistem yang sedang dibangun.

a. Bagan Alur Sitem (Flowchat)

flowchart adalah suatu prosedur atau algoritma yang digunakan untuk menyelesaikan masalah dengan representasi secara simbolik, dalam analisa masalah akan membuat mudah pengguna untuk melakukan koreksi pada bagian yang terlupakan dengan menggunakan flowchart, disamping itu flowchart juga dijadikan sebagai fasilitas dalam berkomunikasi dalam tim suatu proyek dan antara pemrogram yang bekerja maka dibuatlah flowchart sistem lama yang sedang saat ini dipakai dan flowchart sistem baru yang di usulkan oleh peneliti sehingga perbedaan antara sistem yang sedang berjalan di Desa Sumberanyar Kecamatan Paiton dengan sistem baru yang di usulkan bisa lebih jelas dan lebih spesifik

1) Flowchart Sistem Lama

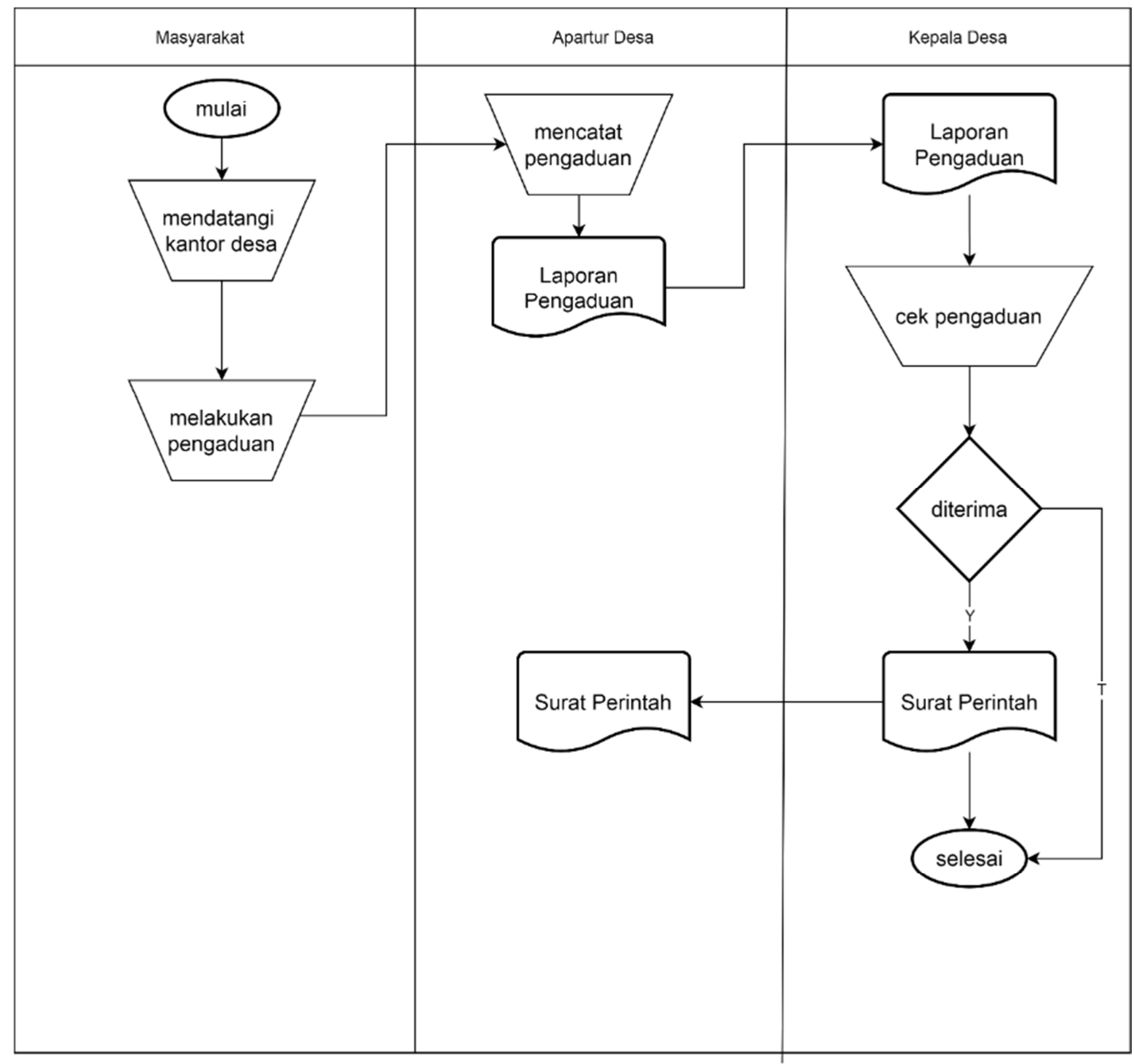

Gambar 2. Flowchart Sistem Lama 
2) lowchart Sistem Baru

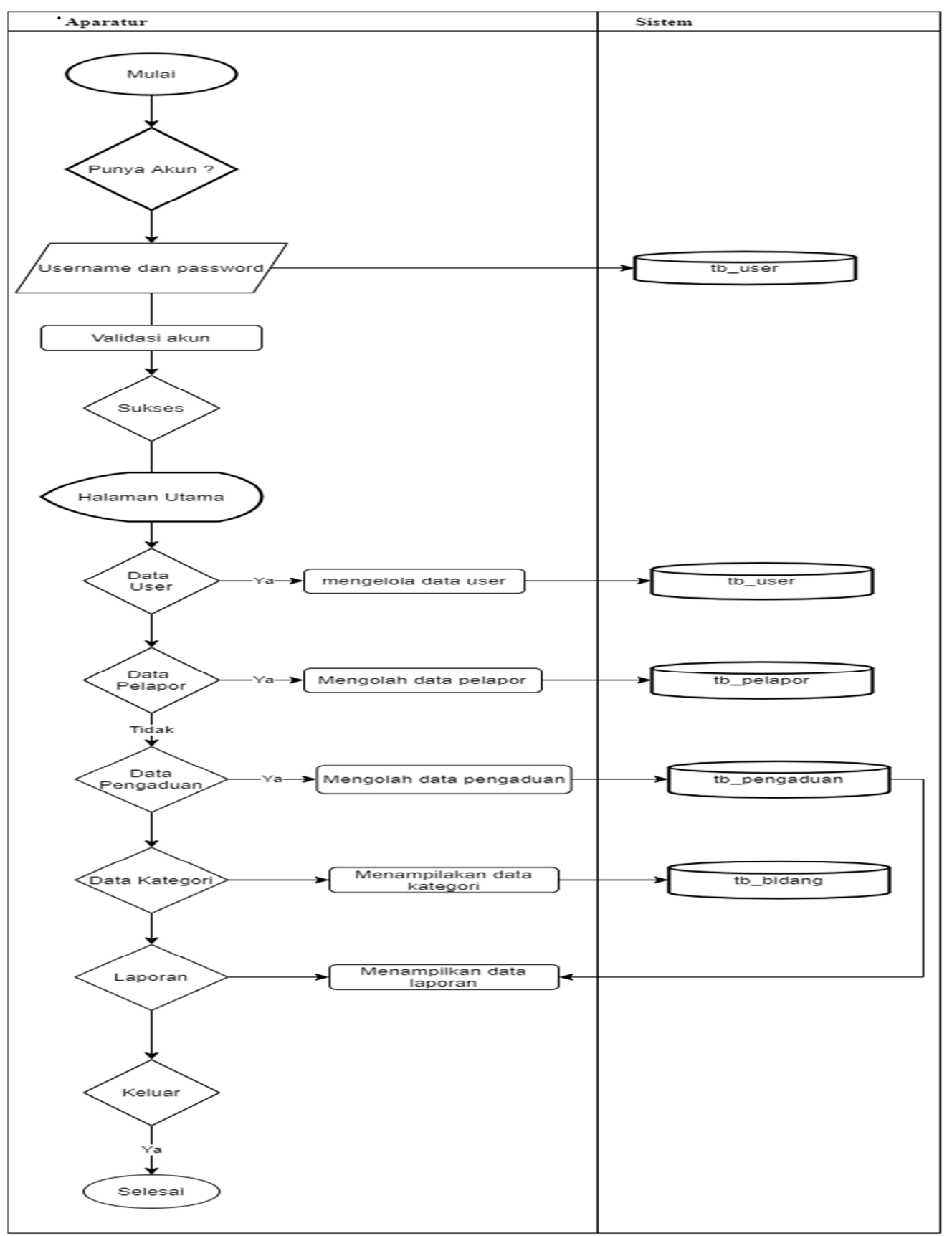

Gambar 3. Flowchart Sistem Lama

\subsection{Implementasi}

a. Form login

Masyarakat yang akan menggunakan aplikasi ini dan harus login terlebih dulu sebelum menggunakan aplikasi ini. 


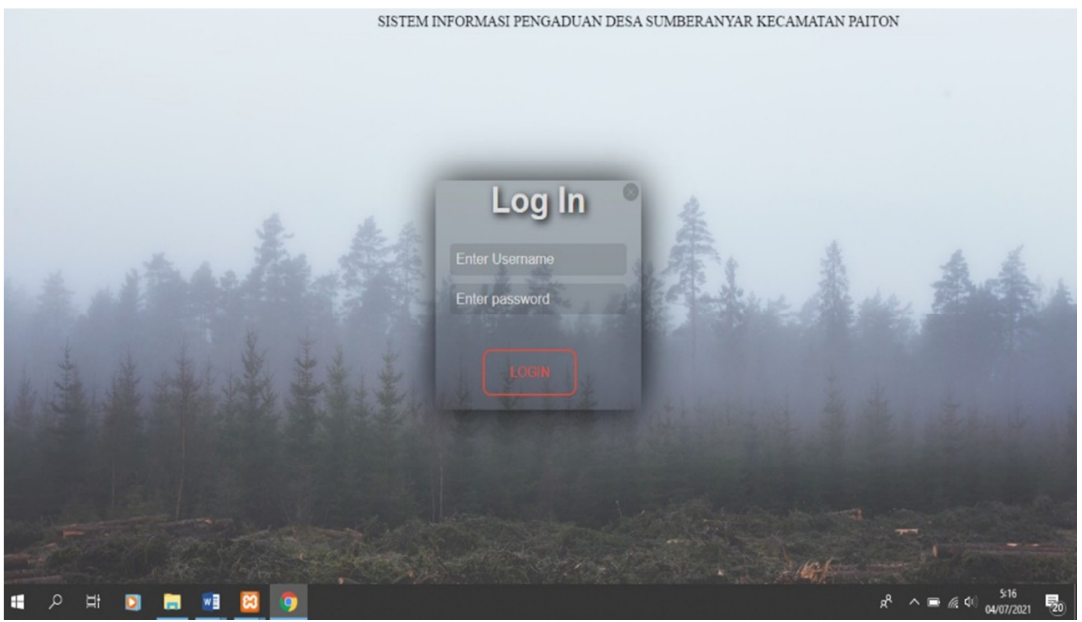

Gambar 4. Form Login

b. Halaman Dashboard

Dashboard adalah form yang akan tampil jika login dari masyarakat sukses tapi jika gagal, masyarakat tidak akan masuk ke dashboard. Dashboard adalah form yang menampilkan fitur-fitur yang ada dalam sistem ini.

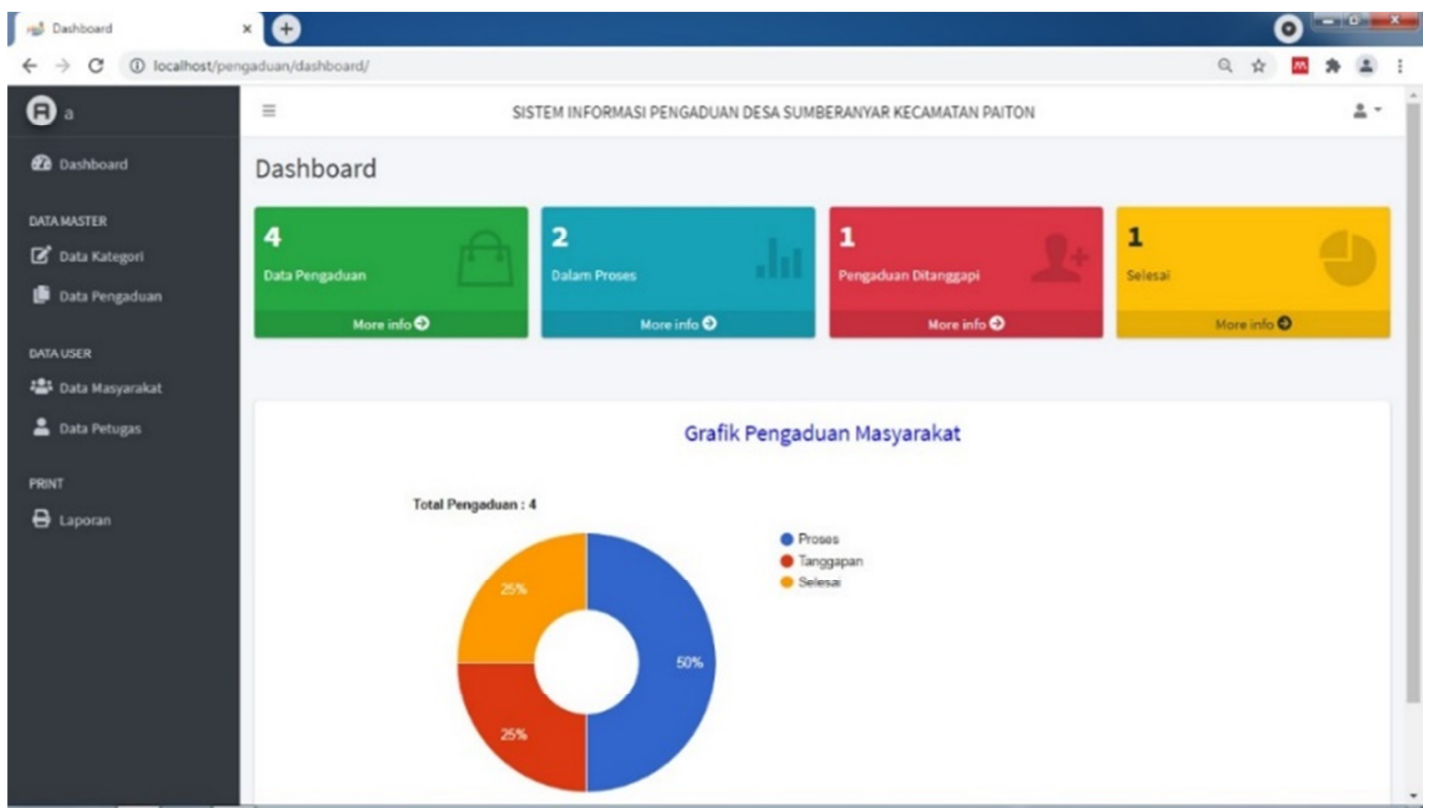

Gambar 5. Halaman Dashboard 
c. Data Kategori

\begin{tabular}{|c|c|c|c|c|c|}
\hline (A) Ruly Amalia & $\equiv$ & \multicolumn{3}{|c|}{ SISTEM INFORMASI PENGADUAN DESA SUMBERANYAR KECAMATAN PAITON } & 2 - \\
\hline 22 Dashboard & \multicolumn{5}{|l|}{ Data Kategori } \\
\hline \multicolumn{6}{|l|}{ DATA MASTER } \\
\hline$\tilde{C}$ Data Kategori & \multicolumn{5}{|l|}{ + Tambah Data } \\
\hline L Data Pengaduan & Show $10 \vee$ entries & \multicolumn{4}{|c|}{ Search: } \\
\hline DATA USER & No $\quad$ t. & Bidang & \multicolumn{2}{|c|}{ Aksi } & \\
\hline 20: Data Masyarakat & 1 & Infrastruktur & $\widetilde{Z}$ Edit & च̄ Hapus & \\
\hline 2 Data Petugas & 2 & Program Keluarga Harapan (PKH) & $\square$ Edit & $\overline{\mathbf{D}}$ Hapus & \\
\hline PRINT & 3 & Bantuan langsung tunai (BLI) & $\square$ Edit & I Hapus & \\
\hline \multirow[t]{2}{*}{ B Laporan } & 4 & Beras Miskin (RASKIN) & $\square$ Edit & $\overline{\boldsymbol{Z}}$ Hapus & \\
\hline & \multicolumn{3}{|c|}{ Showing 1 to 4 of 4 entries } & Previous & Next \\
\hline
\end{tabular}

\section{Gambar 6. Data Kategori}

d. Form Data Pengaduan

Form pengaduan digunakan masyarakat untuk melakukan pengaduan atau aspirasi ke desa sumberanyar kecamatan paiton.

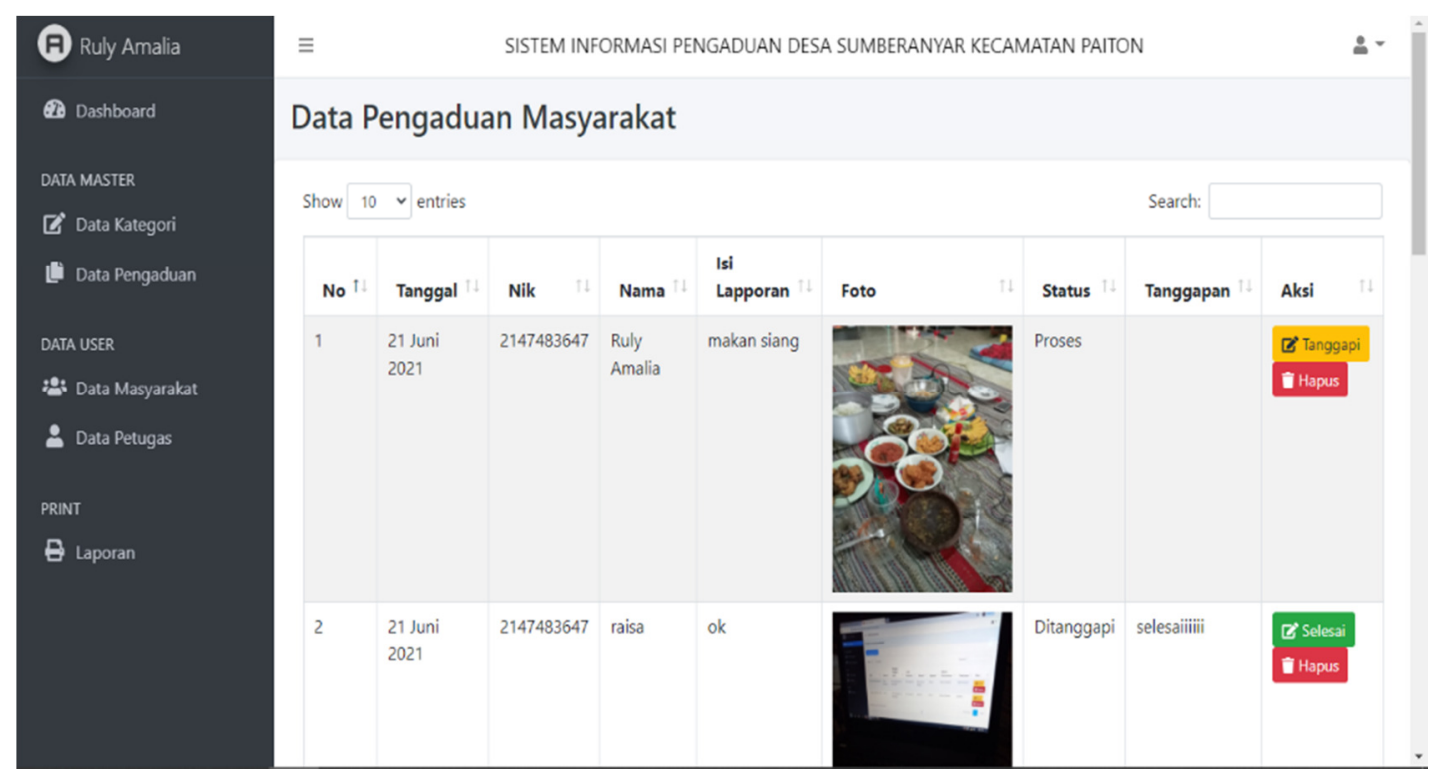

Gambar 7. Data Pengaduan

e. Form Data Masyarakat

Riwayat pengaduan digunakan oleh masyarakat untuk melihat hasil dari pengaduan yang dilakukan.

Amalia, et., al [Aplikasi Monitoring Pelayanan Masyarakat Desa Sumberanyar Kecamatan Paiton Berbasis Web] 


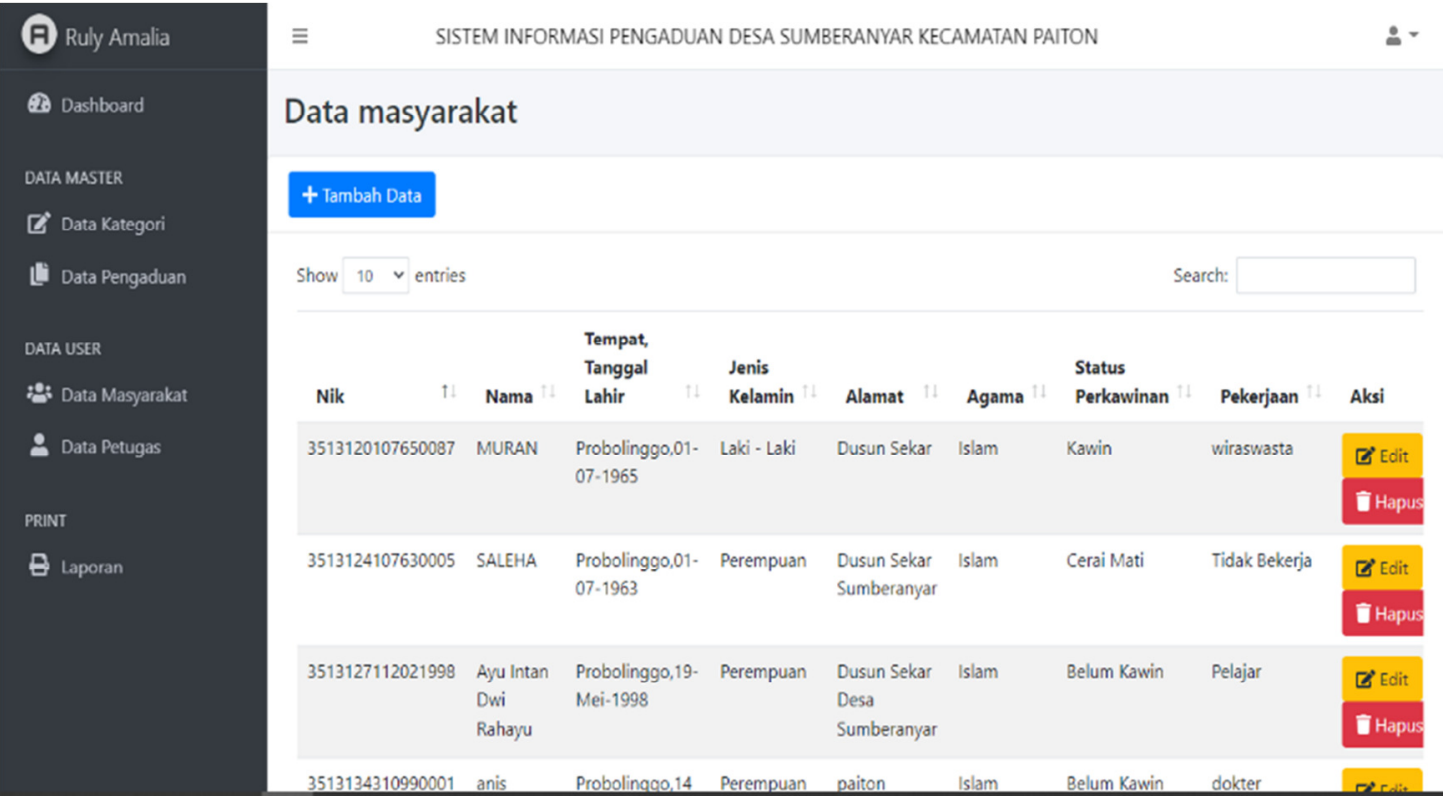

Gambar 8. Form Data Masyarakat

\section{f. Form Data Petugas}

Form gani password bisa masyarakat gunakan untuk mengganti password akun, agar tidak sembarangan orang bisa masuk menggunakan akun orang lain.

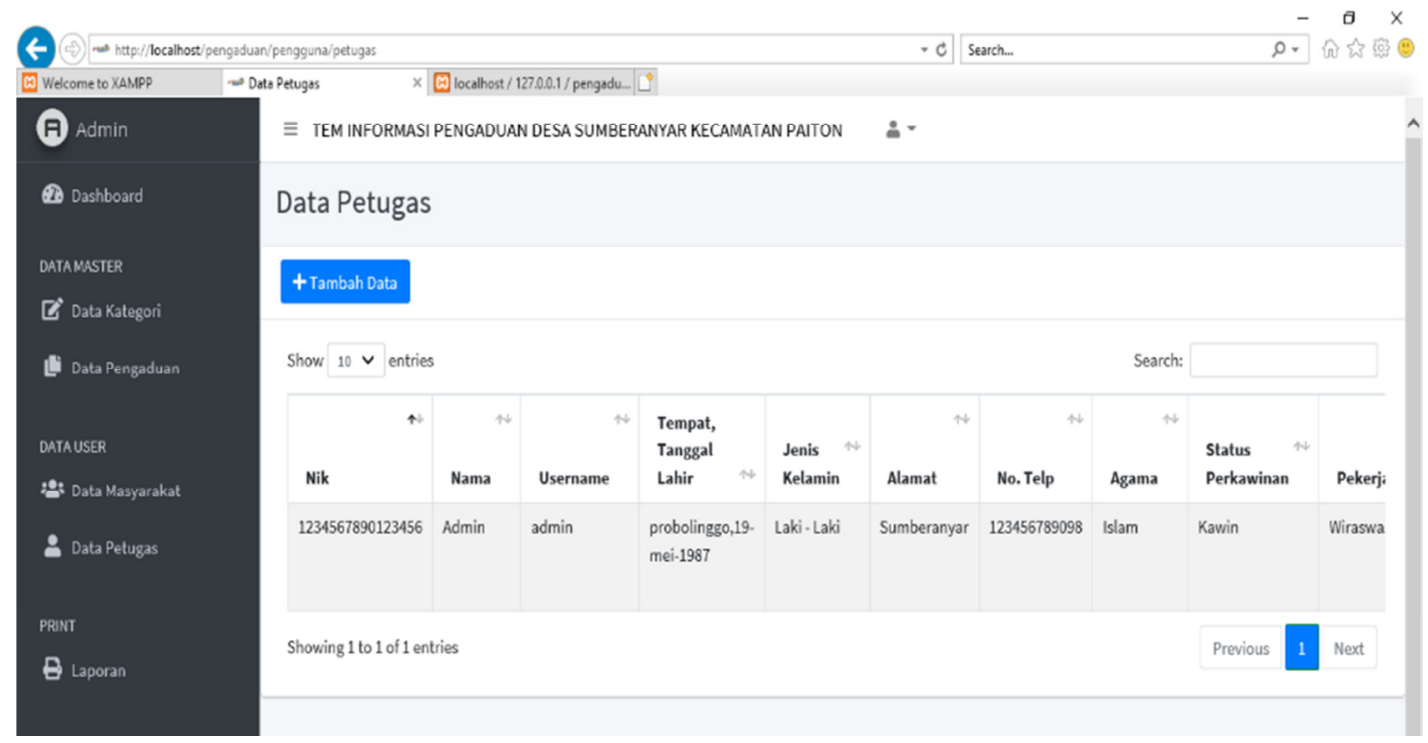

Gambar 9. Form Data Petugas

g. Hasil Laporan Pengaduan

Hasil akhir dari melakukan pengaduan ketika semuanya selesai ditanggapi maka selanjutnya aparatur desa membuat hasil cetak laporan yang berupa file pdf maupun excel. 


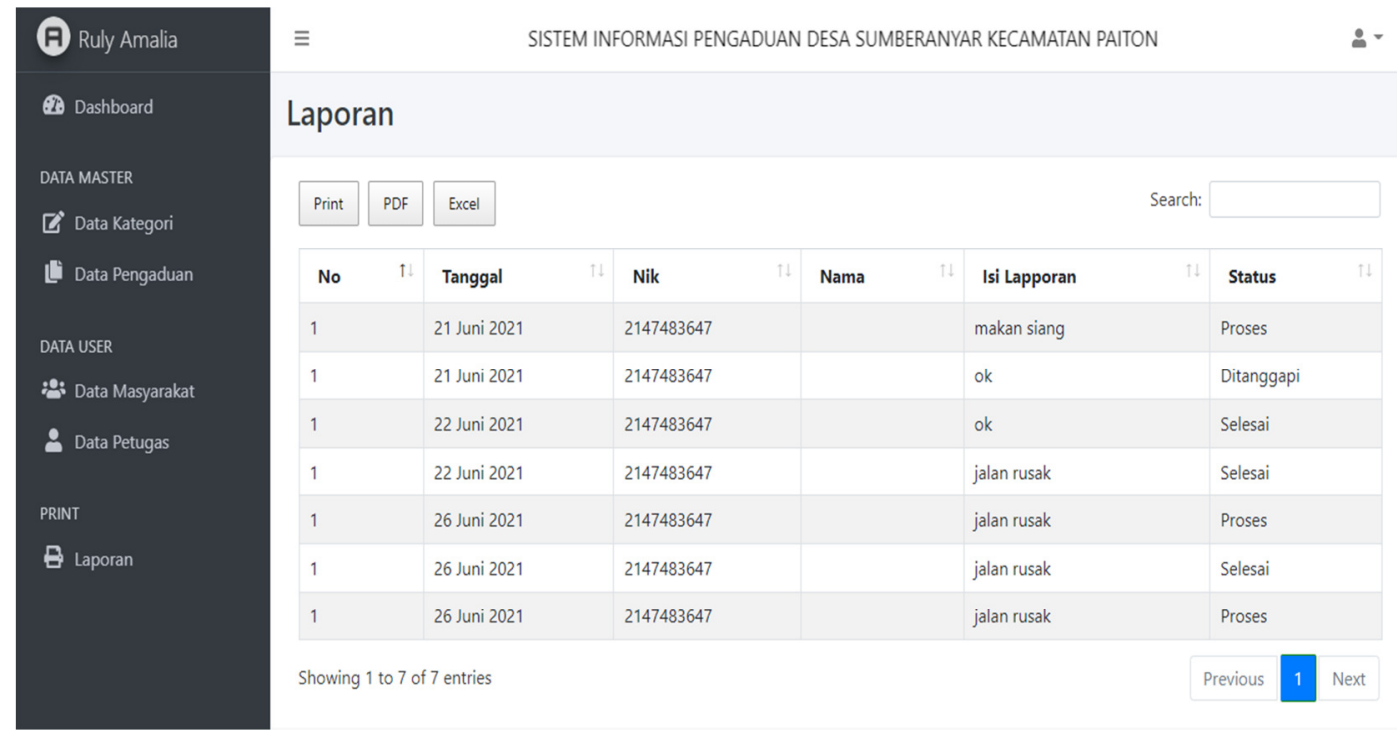

Gambar 10. Laporan Pengaduan

\section{KESIMPULAN}

Setelah dilakukan penelitian dapat ditarik beberapa kesimpulan Pembahasan tentang penerapan Aplikasi Monitoring Pelayanan Masyarakat Desa Sumberanyar Kecamatan Paiton Berbasis Web yaitu bahwa telah dihasilkan suatu sistem sistem informasi yang berbasis Web dengan sebuah aplikasi monitoring. Sistem ini akan menampilkan informasi yang diantaranya seperti informasi masyarakat desa yang melakukan pengaduan kepada aparatur desa, sehingga masyarakat lebih mudah dalam menyampaikan aspirasinya kepada aparatur desa serta sistem yang dibuat berbasis web sehingga aparatur bisa langsung menyampaikan informasi kepada masyarakat serta bisa membantu para warga kapanpun dan dimanapun.

\section{SARAN}

Adapun beberapa hal ini yang bisa menjadi bahan evaluasi bagi peneliti atau pengembangan sistem selanjutnya:

1. Perlu adanya penambahan fitur lokasi, sehingga masyarakat bisa lebih akurat dalam memberikan informasi pengaduan.

2. Perlunya penambahan fitur informasi dari desa, sehingga masyarakat desa sumberanyar mendapatkan informasi lebih cepat dan akurat.

\section{UCAPAN TERIMA KASIH}

Dalam hal ini penulis menyampaikan terimakasih kepada bapak Moh. Toha, S.Pd.I,Mm selaku kepala desa Sumberanyar Kecamatan Paiton yang telah memperbolehkan penulis melakukan penelitian di kantor desa sumberanyar kecamatan paiton.

\footnotetext{
Amalia, et., al [Aplikasi Monitoring Pelayanan Masyarakat Desa Sumberanyar Kecamatan Paiton Berbasis Web]
} 


\section{DAFTAR PUSTAKA}

[1] Pibriana, D., \& Ricoida, D. I. 2017. Analisis Pengaruh Penggunaan Internet Terhadap Minat Belajar Mahasiswa (Studi Kasus: Perguruan Tinggi di Kota Palembang). Jurnal Jatisi (Jurnal Teknik Informatika dan Sistem Informasi), 3(2), 105.

[2] Supriatiningsih, S., Safudin, M., \& Yulianto, E. 2019. Rancang Bangun Sistem Informasi Pelayanan Masyarakat Berbasis Web pada Desa Sambeng Kulon Kabupaten Banyumas. Indonesian Journal on Software Engineering (IJSE), 5(1), 95-103. https://doi.org/10.31294/ijse.v5i1.5868

[3] Salma, S., Pudjiantoro, T. H., \& Umbara, F. R. 2018. Sistem Informasi Monitoring Pelayanan di Badan Pertanahan Nasional Kota Cimahi. Prosiding SNATIF Ke-6 Tahun 2019, 5(2007), 96-101.

[4] Rusdi, Z., \& Trisnawarman, D. 2018. Rekayasa Perangkat Lunak Sistem Monitoring dan Evaluasi Program Pembangunan Desa. Journal of Computer Science and Information Systems, 02(02), 169-177.

[5] Lesva, O., \& Yadi. 2019. Sistem Monitoring Kesehatan Masyarakat Berbasis Web. Jurnal Informanika, l(1), 41-57. http://www.ghbook.ir/index.php? $\mathrm{hl}=\mathrm{en} \& \mathrm{q}=\mathrm{APLIKASI}+\mathrm{PENGENA}$

[6] Tadanugi, I. N. 2019. Peranan Aparatur Desa Dalam Pelaksanaan Pembangunan di Desa Tampemadoro Kecamatan Lage Kabupaten Poso. Jurnal Ilmiah Administratie, 13(september 2019), 1-11.

[7] Hidayatulloh, S., \& Mulyadi, C. 2015. Sistem Pelayanan Administrasi Kependudukan Desa Candigatak Berbasis Web. Jurnal IT CIDA, 1(1), 42-55. http://journal.amikomsolo.ac.id/index.php/itcida/article/view/1

[8] Masturoh, S., Wijayanti, D., \& Prasestyo, A. 2019. Sistem Informasi Akademik Berbasis Web Menggunakan Model Waterfall pada SMK ITENAS Karawang. Jurnal Techno Nusa Mandiri, 15(2), 137. https://doi.org/10.33480/techno.v15i2.923

[9] Ritnawati, Suppa, R., \& Muhallim, M. 2020. Sistem Informasi Pelayanan Masyarakat Berbasis Android pada Kantor Desa Kaliba Mamase. SPEKTA (Jurnal Pengabdian Kepada Masyarakat: Teknologi Dan Aplikasi), 1(2), 95. https://doi.org/10.12928/spekta.v1i2.2860

[10] Stefanus, M., \& Andry, J. D. 2020. Pengembangan Aplikasi E-learning Berbasis Web Menggunakan Model Waterfall pada SMK Strada 2 Jakarta. Jurnal Fasilkom, 10(1), 110. https://doi.org/10.37859/jf.v10i1.1878 